\title{
Meta-analysis of mould and dampness exposure on asthma and allergy in eight European birth cohorts: an ENRIECO initiative
}

\author{
C. G. Tischer ${ }^{1}$, C. Hohmann ${ }^{2}$, E. Thiering ${ }^{1}$, O. Herbarth ${ }^{3}$, A. Müller ${ }^{4}$, J. Henderson ${ }^{5}$, R. GranelI ${ }^{5}$, \\ M. P. Fantini ${ }^{6}$, L. Luciano ${ }^{6}$, A. Bergström $^{7}$, I. Kull ${ }^{7,8}$, E. Link ${ }^{9}$, A. von Berg ${ }^{10}$, C. E. Kuehni ${ }^{11,12}$, \\ M.-P. F. Strippoli ${ }^{11}$, U. Gehring ${ }^{13}$, A. Wijga ${ }^{14}$, E. Eller $^{15}$, C. Bindslev-Jensen ${ }^{15}$, T. Keil $^{2}$, \\ J. Heinrich ${ }^{1} \&$ as part of the ENRIECO consortium
}

${ }^{1}$ Helmholtz Centre Munich, German Research Centre for Environmental Health, Institute of Epidemiology I, Neuherberg, Germany; ${ }^{2}$ Institute of Social Medicine, Epidemiology and Health Economics, Charité University Medical Centre, Berlin, Germany; ${ }^{3}$ Institute of Environmental Medicine and Hygiene, Faculty of Medicine, University of Leipzig, Leipzig, Germany; ${ }^{4}$ Department Proteomics, Helmholtz Centre for Environmental Research, Leipzig, Germany; ${ }^{5}$ School of Social and Community Medicine, University of Bristol, Bristol, UK; ${ }^{6}$ Department of Medicine and Public Health, University of Bologna, Alma Mater Studiorum, Bologna, Italy; ${ }^{7}$ Institute of Environmental Medicine, Karolinska Institutet, Stockholm, Sweden; ${ }^{8}$ Department of Clinical Research and Education, Södersjukhuset, Stokholm, Sweden; ${ }^{9}$ Heinrich-Heine-Universität Düsseldorf, IUF - Leibniz Research Institute for Environmental Medicine, Düsseldorf, Germany; ${ }^{10}$ Department of Paediatrics, Marien-Hospital Wesel, Wesel, Germany; ${ }^{11}$ Institute of Social and Preventive Medicine (ISPM), University of Bern, Division, Bern, Switzerland; ${ }^{12}$ Department of Infection, Immunity and Inflammation, University of Leicester, Leicester, UK; ${ }^{13}$ Institute for Risk Assessment Sciences, Utrecht University, Utrecht, the Netherlands; ${ }^{14}$ Centre for Prevention and Health Services Research, National Institute of Public Health and the Environment, Bilthoven, The Netherlands; ${ }^{15}$ Department of Dermatology and Allergy Centre, Odense University Hospital, Odense, Denmark

To cite this article: Tischer CG, Hohmann C, Thiering E, Herbarth O, Müller A, Henderson J, Granell R, Fantini MP, Luciano L, Bergström A, Kull I, Link E, von Berg A, Kuehni CE, Strippoli M-PF, Gehring U, Wijga A, Eller E, Bindslev-Jensen C, Keil T, Heinrich J \& as part of the ENRIECO consortium. Meta-analysis of mould and dampness exposure on asthma and allergy in eight European birth cohorts: an ENRIECO initiative. Allergy 2011; 66: 1570-1579.

\section{Keywords}

asthma; environment; epidemiology; moulds; pediatrics; rhinitis.

\section{Correspondence \\ Dr. Joachim Heinrich, Institute of Epidemiology, Helmholtz Zentrum München German Research Centre for Environmental Health, Ingolstaedter Landstrasse 1, D-85764 Neuherberg, Germany. \\ Tel.: 498931874150 \\ Fax: 498931873380 \\ E-mail: joachim.heinrich@helmholtz- muenchen de}

Accepted for publication 17 August 2011

DOI:10.1111/j.1398-9995.2011.02712.x

Edited by: Bodo Niggemann

\begin{abstract}
Background: Several cross-sectional studies during the past 10 years have observed an increased risk of allergic outcomes for children living in damp or mouldy environments.

Objective: The objective of this study was to investigate whether reported mould or dampness exposure in early life is associated with the development of allergic disorders in children from eight European birth cohorts.

Methods: We analysed data from 31742 children from eight ongoing European birth cohorts. Exposure to mould and allergic health outcomes were assessed by parental questionnaires at different time points. Meta-analyses with fixed- and random-effect models were applied. The number of the studies included in each analysis varied based on the outcome data available for each cohort.

Results: Exposure to visible mould and/or dampness during first 2 years of life was associated with an increased risk of developing asthma: there was a significant association with early asthma symptoms in meta-analyses of four cohorts [0-2 years: adjusted odds ratios (aOR), $1.39(95 \% \mathrm{CI}, 1.05-1.84)]$ and with asthma later in childhood in six cohorts [6-8 years: aOR, $1.09(95 \% \mathrm{CI}, 0.90-1.32)$ and $3-10$ years: aOR, $1.10(95 \%$ CI, 0.90-1.34)]. A statistically significant association was observed in six cohorts with symptoms of allergic rhinitis at school age [6-8 years: aOR, 1.12 $(1.02-1.23)$ ] and at any time point between 3 and 10 years [aOR, 1.18 (1.09-1.28)]. Conclusion: These findings suggest that a mouldy home environment in early life is associated with an increased risk of asthma particularly in young children and allergic rhinitis symptoms in school-age children.
\end{abstract}


Reviews conducted in the past 10 years have found an increased risk of respiratory and allergic health outcomes in children with a parent-reported damp and mouldy home environment (1-5). Although a small number of collaborative investigations have consistently reported increased risks of asthma, wheeze and allergic rhinitis in children exposed to visible mould (6-8), these previous studies have been primarily cross-sectional, comprised different definitions of exposure and health outcome and assessed the health outcome at a single time point. The Environmental Health Risks in European Birth Cohorts (ENRIECO) initiative included only population-based prospective birth cohort studies and allows for investigation into allergic health outcomes from birth to 10 years of age in a large, comprehensive, longitudinal data set from eight European studies. The objective of this investi- gation was to assess whether early residential exposure to mould/dampness up to 2 years is associated with the development of asthma, symptoms of allergic rhinitis and sensitization in children at different time points between birth and 10 years.

\section{Methods}

\section{Birth cohort characteristics}

ENRIECO is a project conducted within the European Union's Seventh Framework Programme [Theme 6, Environment (Including Climate Change)] focusing on the potential health effects of environmental exposures. For this investigation, eight birth cohort studies with suitable information on

Table 1 Descriptive overview of the eight European birth cohorts

\begin{tabular}{|c|c|c|c|c|c|c|c|c|c|}
\hline $\begin{array}{l}\text { Acronym and key } \\
\text { reference }\end{array}$ & $\begin{array}{l}\text { LEICESTER } \\
\text { (9) }\end{array}$ & $\begin{array}{l}\text { ALSPAC } \\
\text { (10) }\end{array}$ & $\begin{array}{l}\text { BAMSE } \\
(11)\end{array}$ & GINIplus (12) & $\begin{array}{l}\text { PIAMA- } \\
\text { NHS (13) }\end{array}$ & $\begin{array}{l}\text { LISAplus } \\
(14)\end{array}$ & $\begin{array}{l}\text { DARC } \\
(15)\end{array}$ & $\begin{array}{l}\text { CO.N.ER } \\
(16)\end{array}$ & $P$-value \\
\hline Country & UK & UK & Sweden & Germany & $\begin{array}{l}\text { The } \\
\text { Netherlands }\end{array}$ & Germany & Denmark & Italy & \\
\hline First year of recruitment & 1985 & 1991 & 1994 & 1995 & 1996 & 1997 & 1998 & 2004 & \\
\hline$N$ (birth) & 330 & 14057 & 4089 & 5991 & 3182 & 3097 & 562 & 434 & \\
\hline Sex (female) & $48 \%$ & $48 \%$ & $49 \%$ & $48 \%$ & $48 \%$ & $49 \%$ & $49 \%$ & $51 \%$ & 0.777 \\
\hline $\begin{array}{l}\text { Early mould and/or } \\
\text { dampness (0-2 years) }\end{array}$ & $19 \%$ & $67 \%$ & $28 \%$ & $26 \%$ & $55 \%$ & $37 \%$ & $36 \%$ & $13 \%$ & $<0.001$ \\
\hline Early asthma (0-2 years)* & No data & No data & $14 \%$ & $3 \%$ & $4 \%$ & $0.5 \%$ & $24 \%$ & $13 \%$ & $<0.001$ \\
\hline $\begin{array}{l}\text { School-age asthma } \\
\text { (6-8 years) }\end{array}$ & $16 \%$ & $10 \%$ & $9 \%$ & $5 \%$ & $6 \%$ & $5 \%$ & $4 \%$ & No data & $<0.001$ \\
\hline Ever asthma (3-10 years) & $16 \%$ & $10 \%$ & $18 \%$ & $5 \%$ & $9 \%$ & $4 \%$ & $4 \%$ & No data & $<0.001$ \\
\hline $\begin{array}{l}\text { Symptoms of allergic rhinitis } \\
\text { at school-age ( } 6-8 \text { years }) \dagger\end{array}$ & $36 \%$ & $19 \%$ & $14 \%$ & $25 \%$ & $33 \%$ & $24 \%$ & $3 \%$ & No data & $<0.001$ \\
\hline $\begin{array}{l}\text { Ever symptoms of allergic } \\
\text { rhinitis ( } 3-10 \text { years) }\end{array}$ & $36 \%$ & $19 \%$ & $19 \%$ & $27 \%$ & $42 \%$ & $27 \%$ & $3 \%$ & No data & $<0.001$ \\
\hline $\begin{array}{l}\text { Sensitization to } \\
\text { aero-allergens at early school } \\
\text { age }(6-8 \text { years }) \neq\end{array}$ & No data & No data & $25 \%(8)$ & $28 \%(6)$ & $30 \%(8)$ & $27 \%(6)$ & $17 \%(6)$ & No data & $<0.001$ \\
\hline $\begin{array}{l}\text { Sensitization to mould at early } \\
\text { school age (6-8 years) }\end{array}$ & No data & No data & $2 \%()$ & $2 \%(6)$ & $2 \%(8)$ & $0.8 \%(6)$ & $3 \%(6)$ & No data & $<0.001$ \\
\hline Parental allergy§ & $61 \%$ & $72 \%$ & $61 \%$ & $50 \%$ & $40 \%$ & $55 \%$ & $59 \%$ & $51 \%$ & $<0.001$ \\
\hline \multicolumn{10}{|l|}{ Parental education } \\
\hline Low & $57 \%$ & - & $20 \%$ & $13 \%$ & $13 \%$ & $6 \%$ & $19 \%$ & - & $<0.001$ \\
\hline Medium & $26 \%$ & $47 \%$ & $27 \%$ & $29 \%$ & $37 \%$ & $37 \%$ & $65 \%$ & $54 \%$ & \\
\hline High & $17 \%$ & $53 \%$ & $53 \%$ & $57 \%$ & $50 \%$ & $57 \%$ & $16 \%$ & $46 \%$ & \\
\hline Maternal smoking (pregnancy) & No data & $30 \%$ & $13 \%$ & $15 \%$ & $27 \%$ & $18 \%$ & $33 \%$ & $12 \%$ & $<0.001$ \\
\hline $\begin{array}{l}\text { Early SHS exposure } \\
\text { (0-2 years) }\end{array}$ & $29 \%$ & $25 \%$ & $6 \%$ & $15 \%$ & $13 \%$ & $12 \%$ & $21 \%$ & $3 \%$ & $<0.001$ \\
\hline Breastfeeding ( $\geq 4$ months) ${ }^{* *}$ & $27 \%$ & $20 \%$ & $80 \%$ & $51 \%$ & $32 \%$ & $58 \%$ & $20 \%$ & $91 \%$ & $<0.001$ \\
\hline
\end{tabular}

IgE, Immunoglobulin $\mathrm{E}$.

*DARC: High prevalence of early asthma because of high medication intake (medication prescribed for asthma or bronchitis).

†DARC: Low prevalence of school-age symptoms of allergic rhinitis partly because of different assessment methods.

\$Sensitization to aero-allergens (6-8 years): IgE $>0.35 \mathrm{ku} / \mathrm{l}$ for at least one of the measured aero-allergens in each birth cohort (cat dander, dog dander, mite, mould, grass and tree pollen).

§Parental allergy: mother or father having at least one of the following allergic dispositions: asthma, hay fever, atopic eczema, pet allergy and house dust mite allergy (ever).

-SHS: second-hand smoke (maternal smoking).

**Breastfeeding (at least 4 months). 
exposure and health outcomes were included. The cohorts recruited subjects between 1985 and 2004 with a sample size between 330 and 14057 children (Table 1). Most studies were single-centre studies, except two German birth cohorts (LISAplus and GINIplus) and a Dutch birth cohort (PIAMA-NHS). All cohorts were population-based except the PIAMA-NHS cohort that over-sampled nonallergic pregnant women in the NHS component. All cohorts obtained ethical approval from their local review boards.

\section{Definition of exposure and health outcomes}

Exposure was defined as parent-reported mould and/or dampness in any room of the home during the first 2 years of life (Data S1).

We defined seven health end points, based on the comparability across the birth cohort studies (Data S2): 'Early childhood asthma' (0-2 years), 'school-age asthma' (68 years), and 'ever asthma' at any time between 3 and 10 years of life. The asthma definition was based on the ISAAC-related questions (17) and satisfied two of three conditions: physician-diagnosed asthma ever, parent-reported wheezing (last 12 months) and asthma medication (last 12 months). If there was no comprehensive information on 'physician-diagnosed asthma ever', we used 'physician-diagnosed asthma in the past 12 months' for the assessment. School-age and childhood 'symptoms of allergic rhinitis' (68 years) were defined as sneezing attacks, runny, blocked and itchy nose without having a cold.

Sensitization against aero-allergens and mould allergens was available for five of the eight cohorts. Sensitization was defined as having specific Immunoglobulin E (IgE) of at least $0.35 \mathrm{kU} / 1$ to at least one of the measured aero-allergens (cat dander, dog dander, mite, mould allergens, grass or tree pollen) between 6 and 8 years.

\section{Definition of potential confounders}

Individual cohort analyses were adjusted for the following potential confounders: gender, parental atopy, parental educational level at birth (proxy for socio-economic status), maternal smoking during pregnancy, environmental tobacco smoke during the first 2 years of life, breastfeeding (at least 4 months) and early day care attendance. A confounder was considered a risk factor in the adjusted model if it was associated $\left(\chi^{2}\right.$-test, $\left.P<0.1\right)$ with the respective health outcome in at least two birth cohorts.

\section{Statistical analysis}

Logistic regression was used to calculate crude odds ratios (OR) and adjusted odds ratios (aOR) to assess the effect of early exposure to mould and/or dampness on the development of allergic disorders including asthma, symptoms of allergic rhinitis and sensitization to aero-allergens individually for each cohort and combined. Meta-analyses with fixed- and random-effect models were applied to account for the heterogeneity between the cohorts. The number of the studies included varies according to the data available from each individual cohort. The results of the meta-analysis are presented as forest plots with central point estimates and $95 \%$ confidence intervals (CI). We further stratified the analyses by atopic sensitization status and parental allergy.

Statistical analyses were performed using the statistical software R, version R 2.12.2 (The R Foundation for Statistical Computing).

\section{Results}

\section{Study population}

There were considerable variations among the European birth cohorts regarding the distribution of most exposure variables and potential confounders. During the first 2 years of life, exposure to residential mould and/or dampness ranged from $13 \%$ in Bologna, Italy (CO.N.ER), to $67 \%$ in Bristol, UK (ALSPAC). Further, in the Netherlands (PIAMA-NHS), Denmark (DARC) and one German birth cohort (LISAplus), more than one-third of the parents reported exposure to mould and/or dampness at home within the first 2 years of life (Table 1).

\section{Early exposure to visible mould and/or dampness in relation to allergic health outcomes}

The results from the crude and adjusted logistic regression models are presented in Table 2 and Fig. 1.

Among the Danish children, early asthma was reported in $24 \%$ when compared to a lower prevalence in the remaining cohorts. In DARC, the question regarding medication intake referred to any respiratory medication, not only asthma medication, which might partly explain the increased prevalence. Further, the prevalence of symptoms of allergic rhinitis at school age was reported for only $3 \%$ among the Danish children who were assessed during clinical visits by physicians and not by parent-reported symptoms. Owing to these differences in the assessment, the DARC cohort was excluded from the adjusted analysis of asthma and symptoms of allergic rhinitis to minimize classification bias. However, we performed a sensitivity analysis including the DARC cohort and observed no major changes in the summary effects for asthma [ $(0-$ 2 years): aOR, 1.33 (95\% CI, 1.05-1.69), (6-8 years): aOR, 1.39 (95\% CI, 0.90-1.29), (3-10 years): aOR, 1.08 (95\% CI, $0.89-1.32)$ and symptoms of allergic rhinitis (6-8 years): aOR, 1.12 (95\% CI, 1.03-1.23) and (3-10 years): aOR, 1.17 (95\% CI, 1.08-1.26)]. Because of a similar prevalence of allergic sensitization at school age among the cohorts, the DARC cohort was included in the analysis of early exposure to mould and allergic sensitization status at school age.

\section{Asthma}

There was a statistically significant association between early exposure to mould and asthma ( $<3$ years) in adjusted analysis of four cohorts (aOR, 1.39 (95\% CI, 1.05-1.84), Fig. 1A). The Leicester cohort showed a reduced risk of school-age 


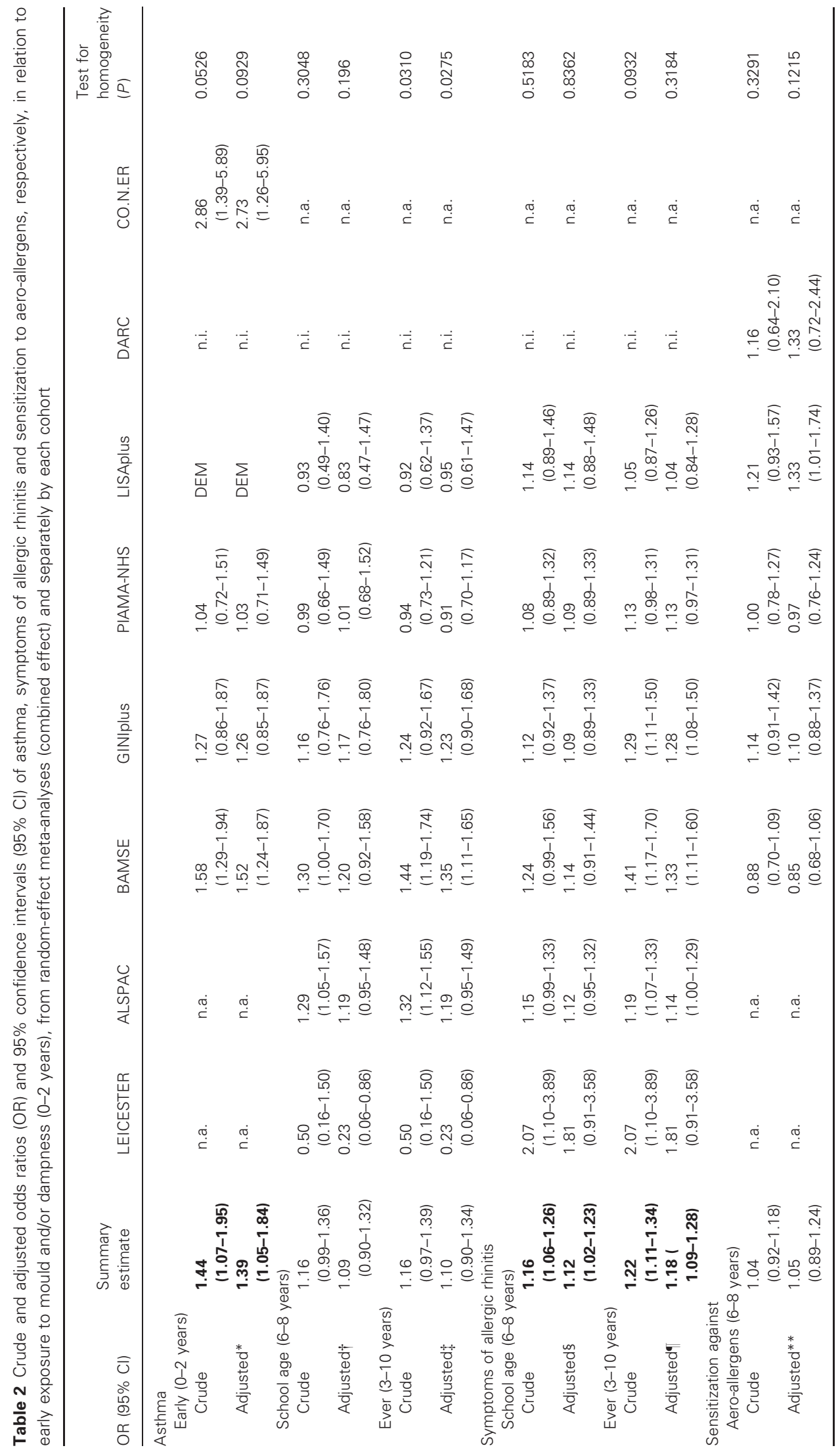




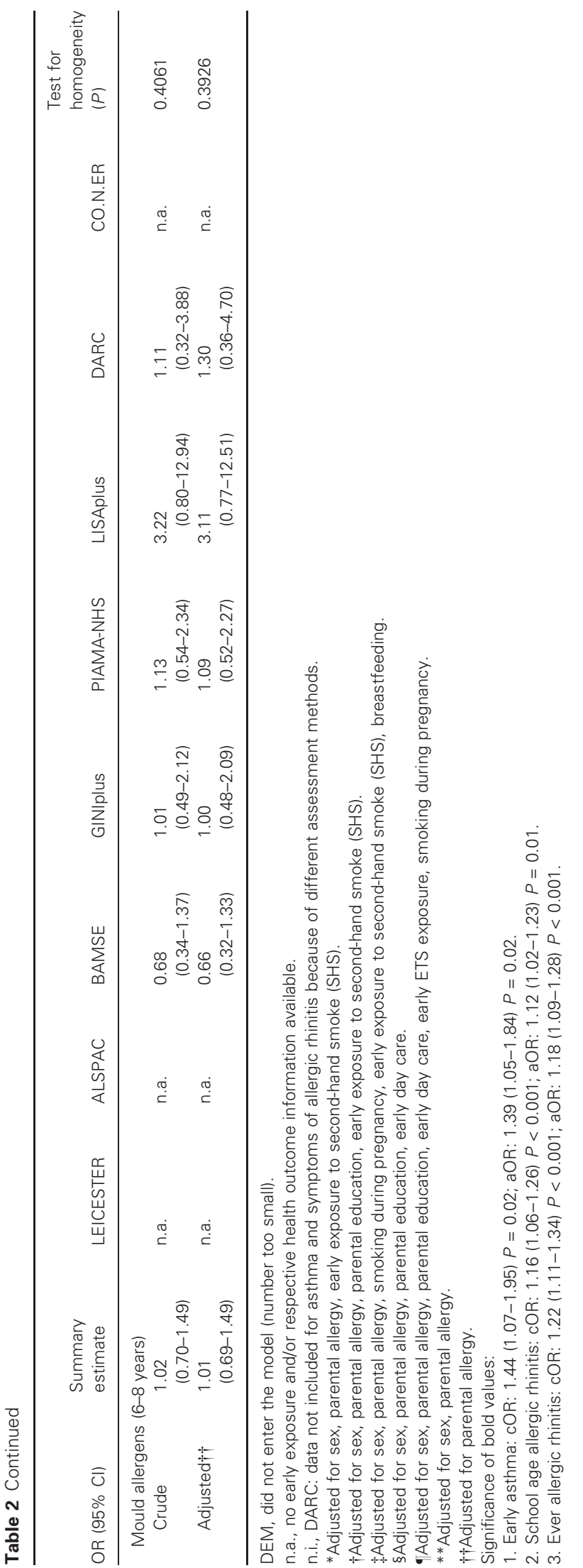

asthma and asthma between age 3 and 10 in children who were exposed to mould/dampness; however, this result should be interpreted with caution because of the small sample size of the included data set from the Leicester cohort. There was statistically significant heterogeneity between the cohorts in the relationship between visible mould and/or dampness and childhood asthma $(3-10$ years, $P<0.05)$.

\section{Symptoms of allergic rhinitis}

The combined OR between early exposure to mould and symptoms of allergic rhinitis during early school age (68 years) and childhood (3-10 years) were significantly increased in adjusted analyses [aOR, 1.12 (95\% CI, 1.021.23 ) and 1.18 (95\% CI, 1.09-1.28)], respectively, Fig. 1B). There was no significant heterogeneity between the cohorts observed.

\section{Sensitization to aero-allergens and mould allergens}

It was possible to model the relationship between early exposure to mould and sensitization (assessed by specific $\operatorname{IgE}$ ) against aero-allergens in general and specifically against mould allergens at $6-8$ years of age for five cohorts. We observed no association between early exposure to visible mould and/or dampness and sensitization against aero-allergens including mould at early school age in adjusted analyses [aOR, 1.05 (95\% CI, 0.89-1.24) and 1.01 (95\% CI, 0.691.49)], respectively (Fig. 1C). Further, we observed no significant heterogeneity between the cohorts.

To improve the comparison of the association between early exposure to mould and asthma outcomes over time, we restricted analyses to those birth cohorts with information at each age category (BAMSE, GINIplus and PIAMA-NHS). The subanalysis revealed similar results - the strongest effect was found for early asthma [0-2 years: aOR, 1.31 (95\% CI, 1.03-1.66), 6-8 years: aOR, $1.15(95 \% \mathrm{CI}, 0.94-1.40)$ and 3-10 years: aOR, 1.15 (95\% CI, 0.90-1.48), respectively].

\section{Stratified analysis}

We further stratified the analysis for sensitization against aero-allergens and parental allergy. The estimates showed a positive but not statistically significant association between early exposure to mould and/or dampness and school-age asthma in children without sensitization to aero-allergens [OR 1.31 (95\% CI, 0.92-1.86), Data S3].

Children with parental allergy and exposure to mould had an increased risk of early asthma symptoms [aOR, 1.49 (95\% CI, 1.00-2.22)], school-age asthma [aOR, 1.14 (95\% CI, $0.97-1.35)$ ] and asthma diagnoses between 3 and 10 years of age [aOR, $1.28(95 \% \mathrm{CI}, 1.12-1.47)]$. Similar effects were observed for school-age and ever symptoms of allergic rhinitis [aOR, $1.14(95 \% \mathrm{CI}, 1.02-1.28)$ and $\mathrm{aOR}, 1.22(95 \% \mathrm{CI}$, 1.11-1.33), respectively], but there was no association between early exposure to mould in relation to sensitization against aero-allergens in children with parental allergy. For children without parental allergy, no association with aller- 


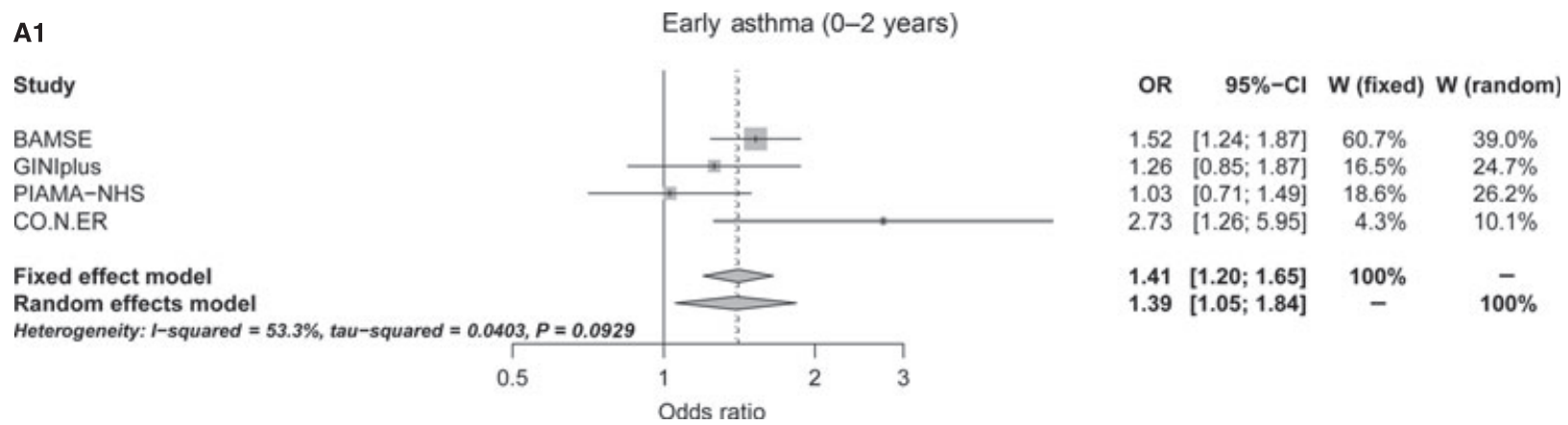

A2

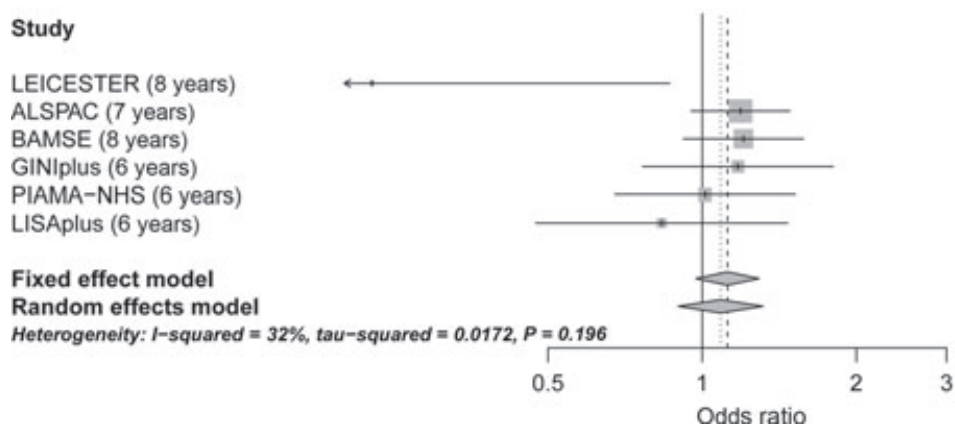

A3

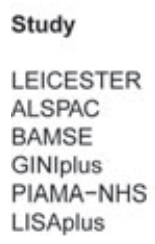

Fixed effect model

Random effects model

Heterogeneity: 1 -squared $=60.3 \%$, tau-squared $=0.0337, P=0.0275$

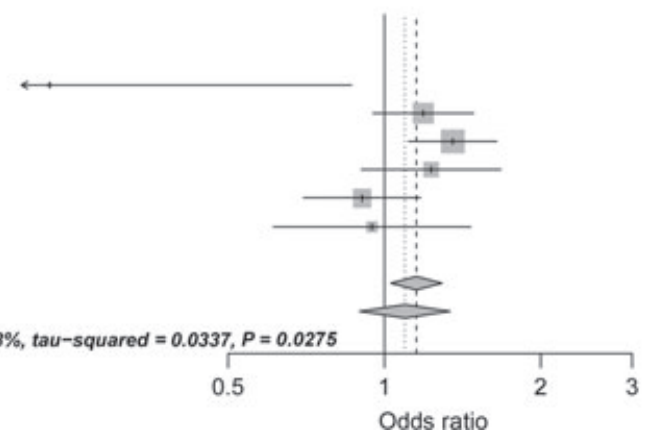

OR

$\begin{array}{rcrc}0.23 & {[0.06 ; 0.86]} & 1.1 \% & 2.0 \% \\ 1.19 & {[0.95 ; 1.48]} & 41.3 \% & 31.7 \% \\ 1.20 & {[0.92 ; 1.58]} & 27.9 \% & 26.3 \% \\ 1.17 & {[0.76 ; 1.80]} & 11.0 \% & 14.6 \% \\ 1.01 & {[0.68 ; 1.52]} & 12.3 \% & 15.9 \% \\ 0.83 & {[0.47 ; 1.47]} & 6.3 \% & 9.5 \% \\ 1.12 & {[0.97 ; 1.29]} & 100 \% & - \\ 1.09 & {[0.90 ; 1.32]} & - & 100 \%\end{array}$

Figure 1 (A) Asthma, (B) Symptoms of Allergic Rhinitis, (C) Allergic Sensitization: Adjusted odds ratios and 95\% confidence intervals (95\% Cl) of asthma, symptoms of allergic rhinitis and allergic sensitization in relation to early exposure to mould and/or dampness (0-2 years), from random-effect meta-analyses (combined effect)

gic, respiratory symptoms was observed; however, there was a significant decreased risk of sensitization against mould allergens at school age [aOR, 0.41 (95\% CI, 0.17-0.98), Data S3].

\section{Discussion}

Our main findings of the meta-analysis of European birth cohorts indicated that early-life exposure to visible mould and/or dampness significantly increased the risk of allergic rhinitis symptoms up to 10 years of age. We also found a and separately by each cohort. For each study, the size of the box represents the variance, the horizontal line the confidence interval of each individual cohort. W (fixed) and W (random) indicate the percentage weight of each cohort contributing to the combined summary estimate. 


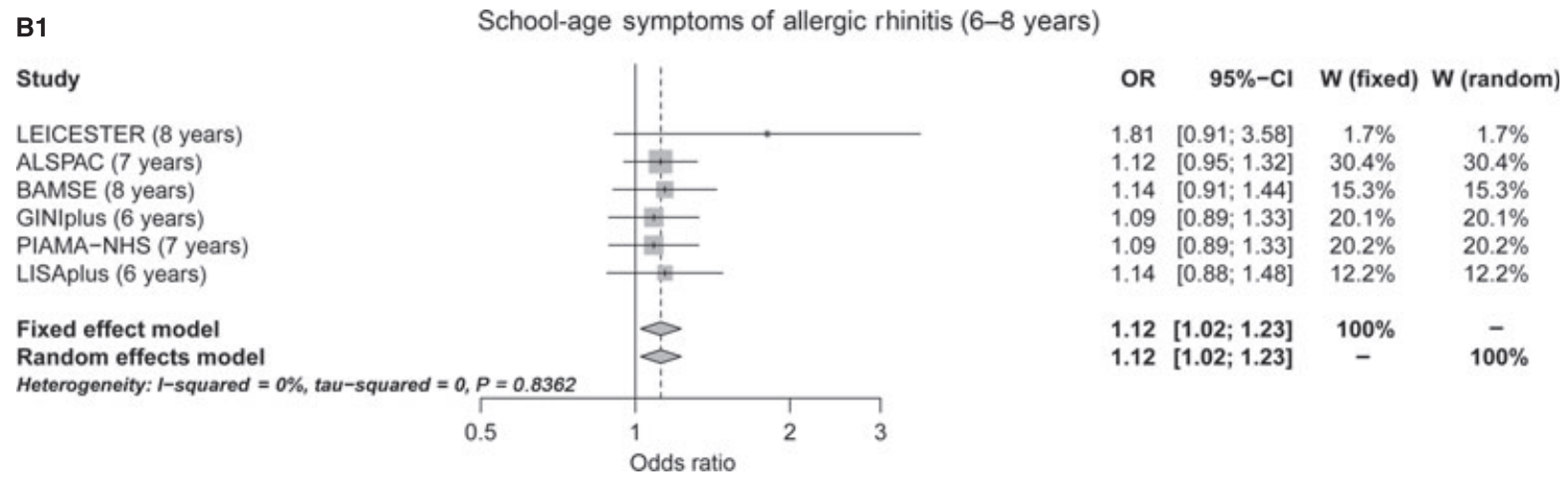

B2

Ever symptoms of allergic rhinitis (3-10 years)

\section{Study \\ LEICESTER \\ ALSPAC \\ BAMSE \\ GINIplus \\ PIAMA-NHS \\ LISAplus}

Fixed effect model

Random effects model

Heterogeneity: 1 -squared $=14.9 \%$, tau-squared $=0.0015, P=0.3184$

0.5

C1

Study

BAMSE ( 8 years)

GINIplus ( 6 years)

PIAMA-NHS ( 8 years)

LISAplus (6 years)

DARC (6 years)

Fixed effect model

Random effects model

Heterogeneity: $I$-squared $=45.1 \%$, tau-squared $=0.0153, P=0.1215$

0.5

School-age sensitization to aero-allergens ( $6-8$ years)

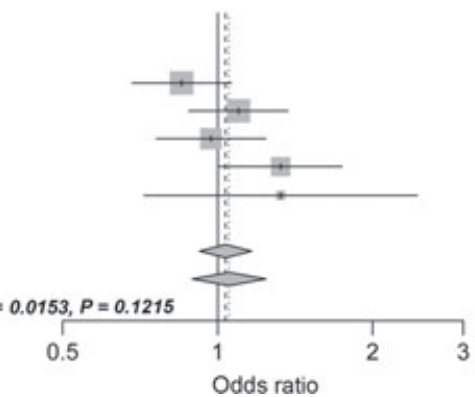

OR $95 \%-\mathrm{Cl}$ W (fixed) W (random)

$1.81 \quad[0.91 ; 3.58] \quad 1.1 \% \quad 1.3 \%$

$1.14[1.00 ; 1.29] \quad 31.1 \% \quad 28.6 \%$

$1.33[1.10 ; 1.60] \quad 14.2 \% \quad 15.2 \%$

$1.28 \quad[1.08 ; 1.50] \quad 19.3 \% \quad 19.7 \%$

$1.13[0.97 ; 1.31] \quad 23.0 \% \quad 22.7 \%$

$1.04[0.84 ; 1.28] \quad 11.3 \% \quad 12.4 \%$

$1.18[1.10 ; 1.27] \quad 100 \%-$

$1.18[1.09 ; 1.28] \quad-\quad 100 \%$

C2

School-age sensitization to mould allergens (6-8 years)

Study

BAMSE ( 8 years)

GINIplus (6 years)

PIAMA-NHS ( 8 years)

LISAplus (6 years)

DARC (6 years)

Fixed effect model

Random effects model

Heterogeneity: 1 -squared $=2.4 \%$, tau-squared $=0.0051, P=0.3926$

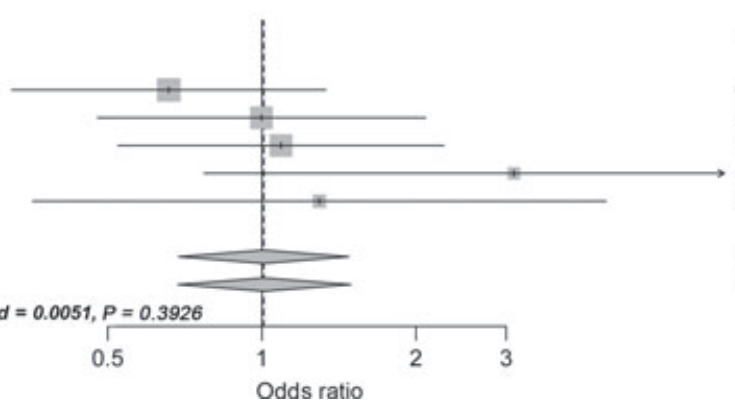

OR $\quad 95 \%-\mathrm{Cl} \quad \mathrm{W}$ (fixed) $\quad \mathrm{W}$ (random)

$0.85[0.68 ; 1.06] \quad 27.8 \% \quad 25.2 \%$

$1.10[0.88 ; 1.37] \quad 27.7 \% \quad 25.2 \%$

$0.97[0.76 ; 1.24] \quad 22.8 \% \quad 23.0 \%$

$1.33[1.01 ; 1.74] \quad 18.1 \% \quad 20.3 \%$

$1.33[0.72 ; 2.44] \quad 3.6 \% \quad 6.3 \%$

$1.04[0.92 ; 1.16] \quad 100 \% \quad-$

OR $95 \%-\mathrm{Cl}$ W (fixed) W (random)

$0.66 \quad[0.32 ; 1.33] \quad 29.4 \% \quad 29.2 \%$

$1.00 \quad[0.48 ; 2.09] \quad 27.0 \% \quad 26.9 \%$

$1.09[0.52 ; 2.27] \quad 27.3 \% \quad 27.2 \%$

$3.11[0.77 ; 12.51] \quad 7.5 \% \quad 7.7 \%$

$1.30[0.36 ; 4.70] \quad 8.8 \% \quad 9.0 \%$

$1.01[0.69 ; 1.48] \quad 100 \% \quad-$

$100 \%$

Figure 1 Continued

This is the largest investigation made into the association of visible mould exposure and allergic disorders, using individual participant data from birth cohorts. The prospective design of these cohort studies is the best approach to assess the temporal sequence between early childhood exposure and health outcomes. Exposure assessment before health outcome 
observation strengthens the independence of both measurements. Crude variables from each of the eight birth cohorts were harmonized. A cohort was eligible for the analysis if there was information available for at least one of the seven defined health outcomes. As a result, not all cohorts contributed to all analysis.

Although visible mould has been consistently associated with allergic outcomes, the causal agents have not been identified (5). 'The enormous diversity of the Fungal Kingdom is well recognized': in 'healthy' indoor environments, the predominant part of fungi is presented by the outdoor air genera Cladosporium, followed by the genera mainly found indoors including Penicillium and Aspergillus $(19,21)$. Once there is moisture or mould, the composition of the fungal profile is shifting mainly to Penicillium and Aspergillus. Species such as Penicillium chrysogenum, Penicillium expansum, Aspergillus versicolor, Aspergillus penicillioides and also Stachybotris chartarum were reported to be detected typically in moisture damaged environments $(22,23)$. It has been shown that fungal species induce inflammatory processes $(5,24)$ and that sensitization to mould allergens is linked to severe asthma (25). In several studies, associations between exposure to spores of Penicillium indoors and an increased risk of respiratory disorders were described $(26,27)$. However, the epidemiological evidence for the association between exposure to specific fungal spores and asthma and allergy remains inconclusive $(5,28)$.

In this investigation, mould exposure was defined as parent-reported visible mould and/or dampness within the homes. This common approach in epidemiological studies might lead to misclassification if moulds were not reported in spite of being present (e.g. hidden behind furniture) or not aerosolized and therefore not relevant to inhaled exposure. As the appearance of visible mould might not be sensitive enough, some studies measured mould exposure via settled house dust or air sampling to reflect the potential inhaled amount (29-31). This objective method is often not realizable in large cohort populations. However, the correlation between visible mould and the airborne concentration of fungal spores seemed to be good (32), and slightly higher indoor spore concentrations were reported for buildings with apparent mould problems $(33,34)$. In summary, the presence of visible mould serves as a good indicator that the indoor environment is out of balance (19).

Our meta-analysis showed that early exposure to mould was significantly associated with asthma, especially in young children. However, this positive effect could be masked by uncertainties of the diagnosis in the first 2 years of life and therefore might be of a transient character. Nevertheless, owing to the asthma definition used in our investigation, satisfying at least two of three allergic conditions implies a more serious health disorder rather than transient symptoms arising from a common cold, and adverse effects of mould exposure on asthma were also observed at later ages.

Although the risk of allergic respiratory disorders was increased in children exposed to mould/dampness, we found no association with allergic sensitization at the same age which is considered to be a major risk factor $(35,36)$. Moreover, after stratifying children by their atopic status, there was a positive, not-statistically-significant association for non-IgE-mediated asthma compared with the nonallergic and nonsymptomatic children. In approximately $80 \%$ of childhood asthma cases, allergy seems to be mediated by IgE antibodies (37), but it is unclear whether the tested aero-allergens are causal agents. The mechanisms of nonallergic asthma result from similar inflammatory changes, but are suggested to be driven by the production of antibodies mainly of the $\mathrm{IgG}, \operatorname{IgA}$ and $\operatorname{IgM}$ isotype after inhalation of large amounts of protein as in mould $(37,38)$. We further observed an increased risk of visible mould exposure in relation to asthma and symptoms of allergic rhinitis in children with parental allergy, but not in children without this hereditary component. In addition, early exposure to mould was observed to decrease the risk of sensitization to mould allergens in children without parental allergy; however, because of the small sample size, these findings should be interpreted with caution. Nevertheless, allergic parents are well advised to ensure healthy indoor air quality and to both remove visible mould or signs of moisture and actively prevent its formation in the first place.

\section{Conclusion}

The results of the first collaborative effort of European birth cohorts with regard to mould and/or dampness indicated an increased risk of subsequent allergic respiratory symptoms in children spending their first years of life in homes with visible mould and/or dampness. To draw a causal relationship is hindered by the variability of microbial components in indoor air. Assessment techniques such as molecular methods and measurements of airborne enzyme activity are considered both highly sensitive and specific and may help to identify patterns of causal agents in relation to asthma and allergy.

\section{Acknowledgment}

The research leading to these results has received funding from the European Union's Seventh Framework Programme (FP7/2007-2013) under Grant agreement No. 226285.

\section{Author contribution}

Christina G. Tischer (first author) carried out statistical analysis, manuscript preparation and revision; Joachim Heinrich designed the study and provided data and commented on the draft; Cynthia Hohmann prepared data (common data base) and commented on the draft; Thomas Keil (MAS), Elisabeth Thiering (LISAplus), Olf Herbarth (LISAplus), Andrea Müller (LISAplus), John Henderson (ALSPAC), Raquel Granell (ALSPAC), Maria Pia Fantini (CO.N.ER), Lorenza Luciano (CO.N.ER), Anna Bergström (BAMSE), Inger Kull (BAMSE), Elke Link (GINIplus), Andrea von Berg (GINIplus), Claudia E. Kühni (LEICESTER), Marie-Pierre F. Strippoli (LEICESTER), Ulrike Gehring (PIAMA-NHS), Alet Wijga (PIAMA-NHS), Esben Eller (DARC) and Carsten Bindslev-Jensen (DARC) provided data, commented on 
the manuscript and participated in the critical revision of the manuscript.

\section{Conflict of interest}

The authors declare no conflict of interest.

\section{Funding}

This work was partly funded by ENRIECO (Environmental Health Risks in European Birth Cohorts), a project conducted within the European Union's Seventh Framework Programme [Theme 6, Environment (Including Climate Change)], Grant agreement No. 226285.

The data collection and study teams of all participating birth cohorts were funded by local and/or national research organizations.

\section{Supporting Information}

Additional Supporting Information may be found in the online version of this article found at: www.wileyonline library.com

Data S1. Definition of early mould and/or dampness exposure in each participating birth cohort.

Data S2. Definition of health outcomes in each participating birth cohort.

Data S3. Mould and/or dampness exposure in relation to asthma and allergy, stratified by sensitization and parental allergy.

Please note: Wiley-Blackwell are not responsible for the content or functionality of any supporting materials supplied by the authors. Any queries (other than missing material) should be directed to the corresponding author for the article.

\section{References}

1. Bornehag CG, Blomquist G, Gyntelberg F, Jarvholm B, Malmberg P, Nordvall L et al. Dampness in buildings and health. Nordic interdisciplinary review of the scientific evidence on associations between exposure to 'dampness' in buildings and health effects (NORDDAMP). Indoor Air 2001;11:72-86.

2. Bornehag CG, Sundell J, Bonini S, Custovic A, Malmberg P, Skerfving S et al. Dampness in buildings as a risk factor for health effects, EUROEXPO: a multidisciplinary review of the literature (1998-2000) on dampness and mite exposure in buildings and health effects. Indoor Air 2004;14:243-257.

3. Institute of Medicine. Damp indoor spaces and health. Washington, DC: Institute of Medicine, 2004

4. Sahakian NM, Park JH, Cox-Ganser JM. Dampness and mold in the indoor environment: implications for asthma. Immunol Allergy Clin North Am 2008;28:485-505, vii.

5. WHO. Dampness and mould. WHO guidelines for indoor air quality. Copenhagen, Denmark: WHO, 2009.

6. Fisk WJ, Lei-Gomez Q, Mendell MJ. Metaanalyses of the associations of respiratory health effects with dampness and mold in homes. Indoor Air 2007;17:284-296.

7. Antova T, Pattenden S, Brunekreef B, Heinrich J, Rudnai P, Forastiere F et al. Exposure to indoor mould and children's respiratory health in the PATY study. $J$ Epidemiol Community Health 2008;62:708-714.

8. Tischer C, Chen CM, Heinrich J. Association between domestic mould and mould components, and asthma and allergy in children: a systematic review. Eur Respir $J$ 2011; May 3 [Epub ahead of print].

9. Kuehni CE, Brooke AM, Strippoli MP, Spycher BD, Davis A, Silverman M. Cohort profile: the Leicester respiratory cohorts. Int J Epidemiol 2007;36:977-985.
10. Baker D, Henderson J. Differences between infants and adults in the social aetiology of wheeze. The ALSPAC Study Team. Avon Longitudinal Study of Pregnancy and Childhood. J Epidemiol Community Health 1999;53:636-642.

11. Wickman M, Kull I, Pershagen G, Nordvall SL. The BAMSE project: presentation of a prospective longitudinal birth cohort study. Pediatr Allergy Immunol 2002;13(Suppl 15):11-13.

12. Zirngibl A, Franke K, Gehring U, von Berg A, Berdel D, Bauer CP et al. Exposure to pets and atopic dermatitis during the first two years of life. A cohort study. Pediatr Allergy Immunol 2002;13:394-401.

13. Wijga A, Smit HA, Brunekreef B, Gerritsen J, Kerkhof M, Koopman LP et al. Are children at high familial risk of developing allergy born into a low risk environment? The PIAMA Birth Cohort Study. Prevention and Incidence of Asthma and Mite Allergy. Clin Exp Allergy 2001;31:576-581.

14. Heinrich J, Bolte G, Holscher B, Douwes J, Lehmann I, Fahlbusch B et al. Allergens and endotoxin on mothers' mattresses and total immunoglobulin $\mathrm{E}$ in cord blood of neonates. Eur Respir $J$ 2002;20:617-623.

15. Johnke H, Vach W, Norberg LA, BindslevJensen C, Host A, Andersen KE. A comparison between criteria for diagnosing atopic eczema in infants. $\mathrm{Br} J$ Dermatol 2005;153:352-358

16. Keil T, Kulig M, Simpson A, Custovic A, Wickman M, Kull I et al. European birth cohort studies on asthma and atopic diseases: II. Comparison of outcomes and exposures - a GA2LEN initiative. Allergy 2006;61:1104-1111.
17. Asher MI, Keil U, Anderson HR, Beasley R, Crane J, Martinez F et al. International Study of Asthma and Allergies in Childhood (ISAAC): rationale and methods. Eur Respir J 1995;8:483-491.

18. Kasznia-Kocot J, Kowalska M, Gorny RL, Niesler A, Wypych-Slusarska A. Environmental risk factors for respiratory symptoms and childhood asthma. Ann Agric Environ Med 2010;17:221-229.

19. Jones R, Recer GM, Hwang SA, Lin S. Association between indoor mold and asthma among children in Buffalo, New York. Indoor Air 2011;21:156-164.

20. Mendell MJ, Mirer AG, Cheung K, Tong $\mathrm{M}$, Douwes J. Respiratory and allergic health effects of dampness, mold, and dampness-related agents: a review of the epidemiologic evidence. Environ Health Perspect 2011;119:748-756.

21. Nevalainen A, Seuri M. Of microbes and men. Indoor Air 2005;15(Suppl 9):58-64.

22. Miller JD, Haisley PD, Reinhardt JH. Air sampling results in relation to extent of fungal colonization of building materials in some water-damaged buildings. Indoor Air 2000;10:146-151.

23. Muller A, Lehmann I, Seiffart A, Diez U, Wetzig $\mathrm{H}$, Borte $\mathrm{M}$ et al. Increased incidence of allergic sensitisation and respiratory diseases due to mould exposure: results of the Leipzig Allergy Risk children Study (LARS). Int J Hyg Environ Health 2002;6:363-365.

24. Chiu LL, Perng DW, Yu CH, Su SN, Chow LP. Mold allergen, pen C 13, induces IL-8 expression in human airway epithelial cells by activating protease-activated receptor 1 and 2. J Immunol 2007;178:5237-5244.

25. Zureik M, Neukirch C, Leynaert B, Liard R, Bousquet J, Neukirch F. Sensitisation to airborne moulds and severity of asthma: 
cross sectional study from European Community respiratory health survey. $B M J$ 2002;325:411-414.

26. Stark PC, Burge HA, Ryan LM, Milton DK, Gold DR. Fungal levels in the home and lower respiratory tract illnesses in the first year of life. Am J Respir Crit Care Med 2003;168:232-237.

27. Rosenbaum PF, Crawford JA, Anagnost SE, Wang CJ, Hunt A, Anbar RD et al. Indoor airborne fungi and wheeze in the first year of life among a cohort of infants at risk for asthma. J Expo Sci Environ Epidemiol 2010;20:503-515.

28. Tischer C, Gehring U, Chen CM, Kerkhof M, Koppelman G, Sausenthaler S et al. Respiratory health in children and indoor exposure to $(1,3)$-\{beta\}-D-glucan, EPS mould components, and endotoxin. Eur Respir J 2011;37:1050-1059.

29. Douwes J, van Strien R, Doekes G, Smit J, Kerkhof M, Gerritsen J et al. Does early indoor microbial exposure reduce the risk of asthma? The Prevention and Incidence of
Asthma and Mite Allergy birth cohort study. J Allergy Clin Immunol 2006;117:1067-1073.

30. Iossifova YY, Reponen T, Bernstein DI, Levin L, Kalra H, Campo P et al. House dust (1-3)-beta-D-glucan and wheezing in infants. Allergy 2007;62:504-513.

31. Iossifova YY, Reponen T, Ryan PH, Levin L, Bernstein DI, Lockey JE et al. Mold exposure during infancy as a predictor of potential asthma development. Ann Allergy Asthma Immunol 2009;102:131-137.

32. Haas D, Habib J, Galler H, Buzina W, Schlacher R, Marth E et al. Assessment of indoor air in Austrian apartments with and without visible mold growth. Atmos Environ 2006;41:10.

33. Hyvärinen A, Reponen T, Husman T, Nevalainen A. Characterizing mold problem buildings: concentration and flora of viable fungi. Indoor Air 1993;3:337-343.

34. DeKoster JA, Thorne PS. Bioaerosol concentrations in noncomplaint, complaint and intervention homes in the Midwest. Am Ind Hyg Assoc J 1995;56:573-580.

35. Sly PD. The early origins of asthma: who is really at risk? Curr Opin Allergy Clin Immunol 2011;11:24-28.

36. Schafer T, Kramer U, Dockery D, Vieluf D, Behrendt H, Ring J. What makes a child allergic? Analysis of risk factors for allergic sensitization in preschool children from East and West Germany. Allergy Asthma Proc 1999;20:23-27.

37. Johansson SG, Hourihane JO, Bousquet J, Bruijnzeel-Koomen C, Dreborg S, Haahtela $\mathrm{T}$ et al. A revised nomenclature for allergy. An EAACI position statement from the EAACI nomenclature task force. Allergy 2001;56:813-824.

38. Johansson SG, Bieber T, Dahl R, Friedmann PS, Lanier BQ, Lockey RF et al. Revised nomenclature for allergy for global use: report of the Nomenclature Review Committee of the World Allergy Organization, October 2003. J Allergy Clin Immunol 2004;113:832-836. 